Article

\title{
Discovery of Transition Rules for Cellular Automata Using Artificial Bee Colony and Particle Swarm Optimization Algorithms in Urban Growth Modeling
}

\author{
Fereydoun Naghibi ${ }^{1}$ and Mahmoud Reza Delavar ${ }^{2, *}$ \\ 1 GIS Department, School of Surveying and Geospatial Engineering, College of Engineering, \\ University of Tehran, Tehran 1439951154, Iran; f.naghibi@ut.ac.ir \\ 2 Center of Excellence in Geomatic Engineering in Disaster Management, \\ School of Surveying and Geospatial Engineering, College of Engineering, University of Tehran, \\ Tehran 1439951154, Iran \\ * Correspondence: mdelavar@ut.ac.ir; Tel.: +98-21-6111-4257 or +98-21-8833-4430 \\ Academic Editor: Wolfgang Kainz \\ Received: 6 September 2016; Accepted: 30 November 2016; Published: 15 December 2016
}

\begin{abstract}
This paper presents an advanced method in urban growth modeling to discover transition rules of cellular automata (CA) using the artificial bee colony (ABC) optimization algorithm. Also, comparisons between the simulation results of $\mathrm{CA}$ models optimized by the $\mathrm{ABC}$ algorithm and the particle swarm optimization algorithms (PSO) as intelligent approaches were performed to evaluate the potential of the proposed methods. According to previous studies, swarm intelligence algorithms for solving optimization problems such as discovering transition rules of $\mathrm{CA}$ in land use change/urban growth modeling can produce reasonable results. Modeling of urban growth as a dynamic process is not straightforward because of the existence of nonlinearity and heterogeneity among effective involved variables which can cause a number of challenges for traditional CA. $\mathrm{ABC}$ algorithm, the new powerful swarm based optimization algorithms, can be used to capture optimized transition rules of CA. This paper has proposed a methodology based on remote sensing data for modeling urban growth with $\mathrm{CA}$ calibrated by the $\mathrm{ABC}$ algorithm. The performance of ABC-CA, PSO-CA, and CA-logistic models in land use change detection is tested for the city of Urmia, Iran, between 2004 and 2014. Validations of the models based on statistical measures such as overall accuracy, figure of merit, and total operating characteristic were made. We showed that the overall accuracy of the ABC-CA model was $89 \%$, which was $1.5 \%$ and $6.2 \%$ higher than those of the PSO-CA and CA-logistic model, respectively. Moreover, the allocation disagreement (simulation error) of the simulation results for the ABC-CA, PSO-CA, and CA-logistic models are $11 \%, 12.5 \%$, and $17.2 \%$, respectively. Finally, for all evaluation indices including running time, convergence capability, flexibility, statistical measurements, and the produced spatial patterns, the ABC-CA model performance showed relative improvement and therefore its superiority was confirmed.
\end{abstract}

Keywords: land use change detection; urban growth model; cellular automata; artificial bee colony

\section{Introduction}

Rapid urbanization caused by increasing urban population and massive immigration to urban areas [1] can lead to land use changes with negative impacts such as the deterioration of land resources, landscape fragmentation, social and environmental problems, and loss of agricultural lands among others [2-6]. It is possible to avoid these impacts through anticipatory planning based on urban land use change modeling $[7,8]$.

Understanding this process is one of the most challenging issues in the geosciences $[9,10]$. Recently, land use change models use the capabilities of spatial analyses within a geospatial information systems 
framework and multi-temporal remotely sensed data to provide a better understanding of the urban systems. The models attempt to find a way to understand the mechanisms of the rate and patterns of land use changes and urban growth, provide a means in which to evaluate current urban systems, and provide planning support in urban growth management $[6,10-15]$. To map and monitor urban land use change, the remote sensing data have been employed successfully to assess variations in land use changes. In the absence of reliable data, the land use maps produced by remote sensing data can be used to anticipate future urban changes $[16,17]$. Thus, to model this process several models have been presented, such as Markov chain models [18,19], spatial logistic regression [20], cellular automata (CA) [21-23], and machine learning and artificial intelligence methods like artificial neural networks (ANN) [24-30], support-vector machine (SVM) [31], and genetic algorithms (GA) [32].

Among the models listed above, CA has arguably been the most popular tool used to simulate urban growth. The CA model has capabilities such as flexibility, the ability to reproduce the dynamics of complex systems, self-organization, and a decentralized nature to face with existing spatial heterogeneity of urban form and the nonlinearity of urban growth driving forces. However, in considering dynamic phenomena such as urban land use change processes, the calibration of CA (discovering CA transition rules) is very tedious because of various existing involved parameters with heterogeneity and nonlinearity properties [33-35]. A number of methods have been presented for CA calibration including statistical methods such as multi-criteria evaluation (MCE) or logistic regression (LR) [20,21], Markov chain [36-38], fuzzy logic theory [39], artificial neural networks (ANN) [40-42], support vector machines (SVM) [43], and genetic algorithms (GA) [44].

Based on previous research, these methods have some drawbacks such as assuming linear relationships among the spatial variables in statistical methods [22], subjectivity in the selection of fuzzy membership functions and rules, as well as dependency of outcomes to these functions in fuzzy logic theory [39], and being trapped at a local minimum, over fitting, and having the black box nature of ANNs and SVM [31,40,41,43]. Furthermore, most CA calibration methods use mathematical equations to discover the transition rules. In estimation of the values of mathematical parameters, some uncertainties are involved $[45,46]$. To overcome the previously mentioned limitations, using CA models integrated with swarm intelligence (SI) methods hold promise for urban growth modeling such as ant colony optimization (ACO) [45,47], particle swarm optimization (PSO) [34], bee colony optimization (BCO) [48], and the cuckoo search (CS) algorithm [46]. These methods can consider the complex non-linear processes of urban growth efficiently and produce simulation results with higher accuracies than those of other methods [34,49].

Among the SI methods, the artificial bee colony (ABC) algorithm, proposed by Karaboga in 2005 [50], is one of the most successful algorithms used in optimization problems because of its flexibility, robustness, ease of implementation, and the need for fewer control parameters [51-54]. Recently, in the area of numerical optimization algorithms, $\mathrm{ABC}$ has shown better results in performance and computational efficiency compared with those of the other evolutionary algorithms [53]. To the best of our knowledge, using the ABC algorithm has not been applied to calibrate CA models for modeling urban growth or compared to other popular SI algorithms (e.g., PSO) yet. Considering the advantages of the $\mathrm{ABC}$ algorithm, this paper integrated the $\mathrm{CA}$ model with the $\mathrm{ABC}$ algorithm to investigate optimum transition rules of $\mathrm{CA}$. Although the $\mathrm{ABC}$ algorithm has received a lot of attention in solving optimization problems, there are few studies that have used it in urban growth modeling or compared its capabilities with other similar algorithms. Therefore, there is a need to explore the integration of $\mathrm{ABC}$ and $\mathrm{CA}$ in urban growth modelling, compare its performance with other similar algorithms, and examine how these models/algorithms can predicate possible future urban growth.

Several studies have demonstrated that the PSO algorithm is a powerful optimization technique that can obtain the optimum global pattern and improve locational accuracy in discovering transition rules of CA in land use change and urban growth modeling [34,55]. In this paper, we used the PSO-CA method to evaluate the ABC-CA method. We compared these approaches for urban growth modeling to understand urban growth pattern. This paper attempts to (1) propose a novel approach in urban 
modelling with the CA method calibrated by the ABC algorithm to overcome the mentioned methods' drawbacks and (2) compare the proposed method performance with the PSO-CA method as a similar method and with the CA-logistic as a conventional method. The two models were tested on Urmia, Iran to simulate its future urban growth patterns. The city is located in the northwest of Iran. In the last five decades, the population of Urmia has increased by more than 10 times while its area increased by about 27-fold [56], thereby the city represents a prime candidate for the consideration of rapid urbanization.

\section{Urban Growth Modeling by CA}

In the context of land use change, urban growth is affected by socio-economic and physical conditions, transportation status, environmental challenges, and so on [57]. Urban growth models attempt to estimate future urban boundaries in a planned way to avoid the negative effects of urban expansion. A CA-based urban growth model is commonly used because of its capabilities. CA models usually employ accessibility, neighborhood, suitability, and zoning status [57]. Conceptually, defining transition rules and neighborhood status, and determining restrictions and potential areas for development and random effects are major components of CA, as presented in Equation (1) [22,58,59]:

$$
P_{i j}^{t}=S_{i j}^{t} \times \Omega_{i j}^{t} \times \operatorname{Con} \times e_{r}
$$

where $P_{i j}^{t}$ is the development potential for cell $i j ; S_{i j}^{t}$ is the suitability of cell $i j$ for changing based on relevant factors at times $t ; \Omega_{i j}^{t}$ is the effect of the neighborhood development density; $e_{r}$ is a stochastic disturbance term for unknown errors; and Con are the constraints referring to the influencing factors, which exclude urban growth in some areas, such as environmental sensitive areas or mountainous areas. It is a conditional function and becomes true when the cell suitability for development is found [40]. The calculated development potential is compared with a threshold value based on future land demand to decide whether a non-urban cell can be converted to an urban cell at time $t+1[22,34]$.

However, determining transition rules (or calibrating CA) becomes challenging and complicated when CA modeling is used to simulate a dynamic process such as urban growth modeling because of dealing with several heterogeneous and nonlinear variables and the complex relationships of effective land use conversion parameters [57,60-62]. Among various methods to calibrate CA models, researchers have been able to solve the complex problems by SI algorithms such as ABC and PSO in order to overcome their inherent limitations such as subjectivity, black box nature, and linearity assumptions among effective urban growth factors [34]. The artificial bee colony (ABC) algorithm is one of the most successful SI algorithms used in optimization problems and can be used in calibrating $\mathrm{CA}$ for urban growth modeling because of its high performance. The following sections elaborate the original $\mathrm{ABC}$ and $\mathrm{PSO}$ algorithms for calibrating CA and investigating their comparison.

\section{Artificial Bee Colony Algorithm}

$\mathrm{ABC}$ algorithm is inspired by the foraging behavior of real honey bees for solving optimization problems [50]. The ABC algorithm is a robust, flexible, high performance method and few control parameters are required [54,63]. In this algorithm, three kinds of bees comprising employed bees, onlooker bees, and scout bees try to capture and store the greatest amount of nectar (food) in the hive [52]. The original $A B C$ algorithm for solving optimization problems performs the following steps [51-53,64,65]. The initial food sources positions (solutions) are produced by random initialization (Equation (2)):

$$
X_{i j}=X_{j}^{\min }+\operatorname{rand}(0,1)\left(X_{j}^{\max }-X_{j}^{\min }\right)
$$

where $i=1, \ldots, S N, j=1, \ldots, D$. SN is the number of solutions (food sources) and $D$ represents the number of optimization parameters. In the original $A B C$ algorithm as a population-based algorithm, determination of the initial population is the major step which is randomly performed. This means that there is no initial information regarding the solution. The improvement in configuration of the initial population of the $\mathrm{ABC}$ algorithm can influence the convergence of the algorithm and quality of 
the results [63]. Using chaotic maps in the initialization process of the $A B C$ algorithm can generate a proper initial population [66]. The chaotic maps can be used to enhance the population diversity by exploiting the search space information. The chaotic routines as a sinusoidal iteration process (Equation (3)) can be utilized to make an effective initialization approach [63]. Therefore, in this paper, the initial population is produced by the performance of a chaotic routine; in order to improve the initial population, Equation (4) is used instead of Equation (2).

$$
\begin{gathered}
\text { Chaot }_{k+1}=\operatorname{Sin}\left(\pi \text { Chaot }_{k}\right), \quad \text { Chaot }_{k} \in(0,1), i=0,1, \ldots, I \\
X_{i j}=X_{j}^{\text {min }}+\text { Chaot }_{k, j}\left(X_{j}^{\text {max }}-X_{j}^{\text {min }}\right)
\end{gathered}
$$

In the next step, the employed bees apply some modifications on the positions of the food sources according to their local information in order to produce new-found food sources. The proposed solution is calculated based on new-found food sources. The food source $V_{i j}$ (Equation (5)) is located within the neighborhood of every food source $X_{i j}$.

$$
V_{i j}=X_{i j}+\varphi_{i j}\left(X_{i j}-X_{k j}\right)
$$

where $j$ is a random number in $(1, D)$ ( $D$ represents the number of optimization parameters) and $k \in\{1,2, \ldots, S N\}$ is a random index that should differ from $i . \varphi_{i j}$ represents a uniformly distributed real number in $(-1,1)$ that controls production of the food source location around $X_{i j}$. A better solution between $X_{i j}$ and $V_{i j}$ is selected in the next stage by Equation (6):

$$
\text { fitness }_{i}=\left\{\begin{array}{ll}
\frac{1}{1+f_{i}} & \text { if } f_{i} \geq 0 \\
1+a b s\left(f_{i}\right) & \text { if } f_{i}<0
\end{array}\right\}
$$

where $f_{i}$ is the cost value of the produced solution $i$ and $a b s$ is the absolute value. The "greedy solution" is made based on the profitability between $X_{m n}$ and $V_{m n}$. Then a greedy selection based on profitability is performed between $X_{i j}$ and $V_{m n}$. Probability values for solution $X_{i j}$ are calculated by Equation (7):

$$
p_{i}=\frac{\text { fitness }_{i}}{\sum_{i=1}^{S N} \text { fitness }_{i}}
$$

In this algorithm, a random real number in the range of $[0,1]$ is produced for each source (solution). If the calculated probability value for a food source is greater than the random number, then the onlooker bee performs a modification on the position of the food source with Equation (5). In the next step, exhausted food sources are identified and the new food source is replaced by the scout bee. The best solution until this stage is stored. The next iterations are started, and the previous steps are repeated until reaching the termination criterion.

However, the $\mathrm{ABC}$ algorithm has different dimensions based on the type of optimization problem by which only one of its dimensions is randomly selected to be changed at each iteration. To improve the performance of the algorithm, researchers applied $A B C$ to perform optimizations in multiple dimensions. Applying changes in the value of the dimensions at each repeat of the $\mathrm{ABC}$ algorithm can lead to a better performance [67]. In this research, this strategy was used to improve the performance of the $\mathrm{ABC}$ algorithm in calibrating $\mathrm{CA}$. Some changes in multiple dimensions were applied and the results were reviewed. Based on various tests, changes in four dimensions produced better results which are applied to the original $\mathrm{ABC}$ algorithm to solve the $\mathrm{CA}$ calibration problem in urban growth modeling. The proposed modeling framework includes a generic urban growth model based on $\mathrm{CA}$, which is integrated with the $\mathrm{ABC}$ module for discovering the optimal CA transition rules. Figure 1 shows a flowchart of the proposed ABC-CA model for the urban growth modeling. In this research, population size, the number of employed bees and the number of onlooker bees were set to 100,50, and 50, respectively. Dimension in the proposed ABC-CA model is set to 7 showing the number of 
spatial variables and limitation conditions (distance from business center, distance from road networks, distance from population centers, land use, environmental sensitive areas, slope, and elevation maps). Our proposed model was repeated 350 times.

As previously mentioned, spatial variables in the urban growth phenomenon have heterogeneity and nonlinearity attributes. In the first step, the involved geospatial layers are prepared based on the urban growth driving force parameters. Then, the initialization of the coefficients of the involved layers is performed by the bees with chaotic maps (initial transition rules of CA). Next, based on the CA specification and LR, the conversion potential of any pixel to change its state to an urban pixel is calculated. For every bee, a new layer is produced according to the calculated potential. By comparing the produced layers, the best bee is selected in the first iteration. Based on the selected bee, new transition rules are updated. In the next iterations, until the optimal solution is produced, the above-mentioned steps are repeated.

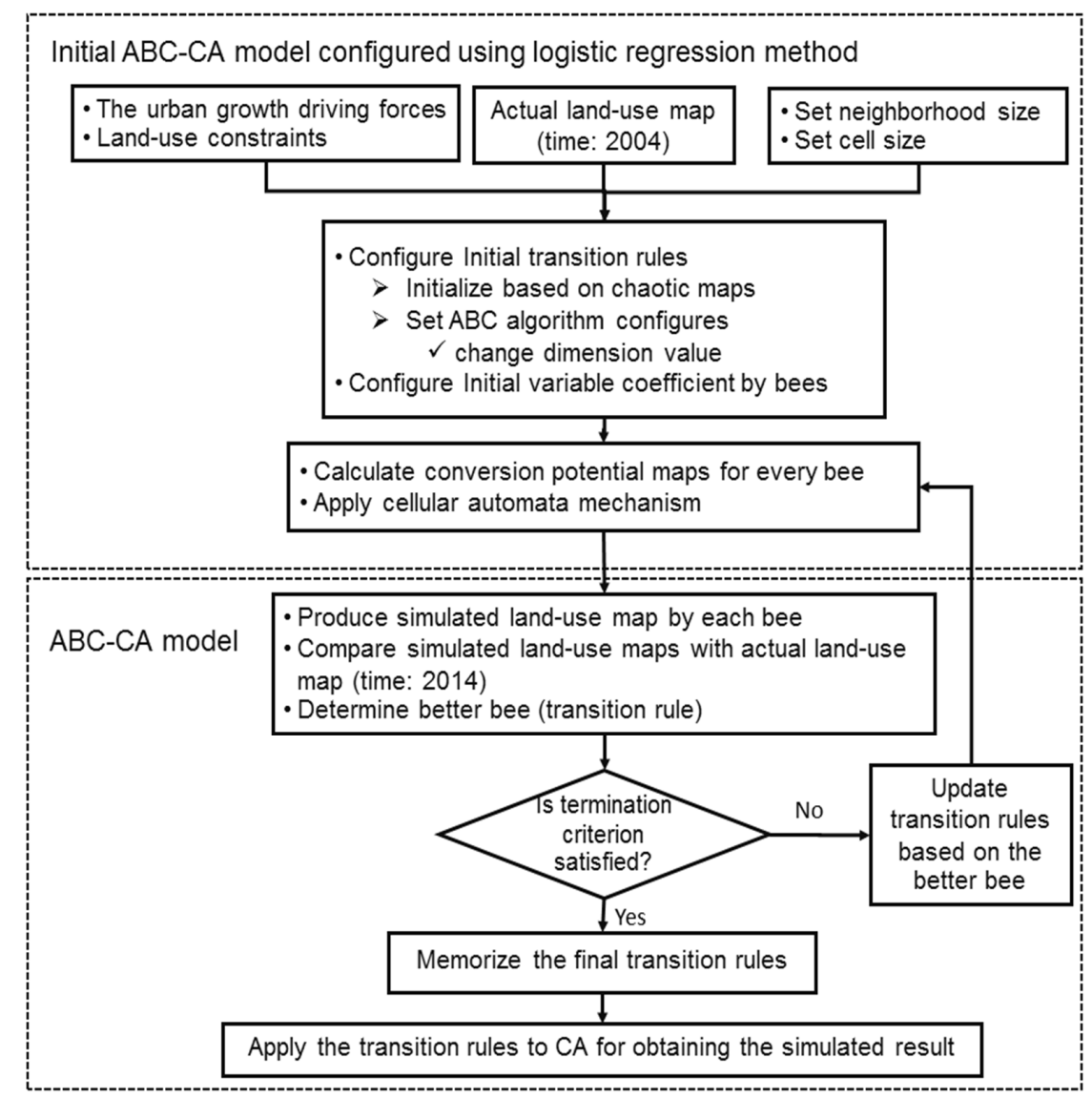

Figure 1. The proposed ABC-CA model. ABC, artificial bee colony; CA, cellular automata.

\section{Particle Swarm Optimization Algorithm}

Particle swarm optimization (PSO) was introduced by Kennedy and Eberhart (1995) based on swarm intelligence and inspired by the foraging behavior of natural swarms such as birds and fish [68]. PSO is a proper algorithm for calibrating urban CA because of its abilities to obtain the optimum global pattern and reduce the simulation uncertainties. Therefore, CA can use this approach to obtain transition rules $[34,49]$.

In PSO, there are n particles with the capability of moving around a supposed D-dimensional search space $[69,70]$. Every effective factor influencing urban growth can be considered as a dimension of the search space. So, the total number of these factors is equal to D. In the search space, each particle is related to feasible parameters consisting of CA transition rules [34,49]. The initial values for 
positions and velocities of particles are assigned randomly [52]. The position and velocity of each particle is adjusted by its individual experience and that of other particles. Then, the fitness value is calculated by a fitness function which determines the optimum position of each particle. [34,70,71]. The fitness function, for example, urban growth modeling, can be built by the accumulative difference between the simulated outcomes produced based on the traditional LR model and corresponding real values. This function is defined based on effective factors influencing urban growth and their probabilities. Finally, the algorithm will achieve the global best particle positions corresponding to the best parameters at calibrating an urban growth CA model. Figure 2 shows the flowchart of the proposed PSO-CA model for urban growth modeling.

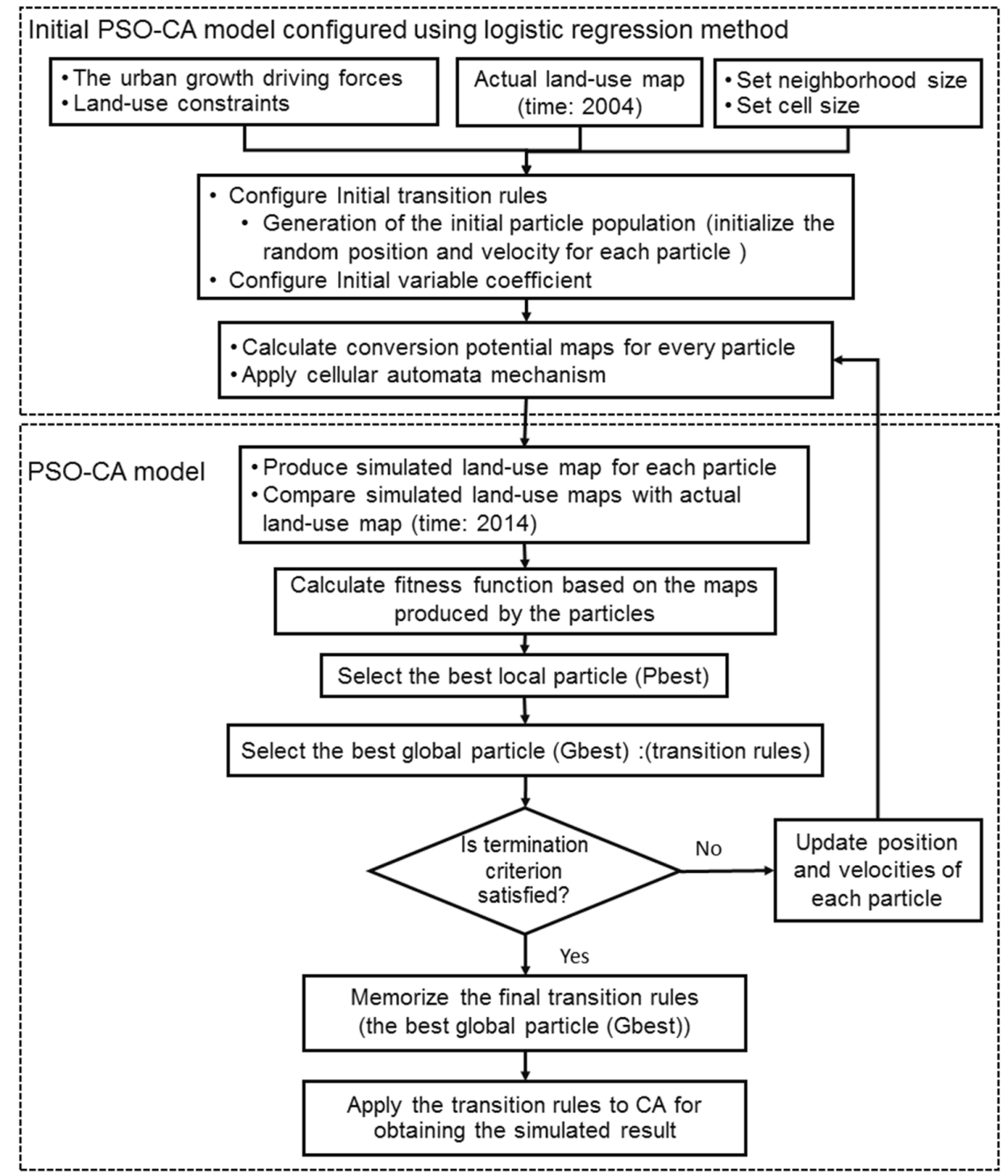

Figure 2. The proposed PSO-CA model. PSO, particle swarm optimization.

\section{Study Area and Datasets}

In this study, for calibrating CA, it is integrated with two SI algorithms including PSO and ABC. The models are tested using data for Urmia, Iran to simulate its future urban growth pattern. The city is located in the northwest of Iran. This study area is an important geographical region in the sense that it is located bordering Turkey and Iraq (Figure 3). This situation has led to economic growth of the region over the years. The region's dominant economy relies on agriculture and recently some industrial activities have begun. In the past five decades, the population of Urmia has increased by more than 10 times while its area increased by about 27-fold [56]. This means that Urmia has experienced rapid urban growth. 


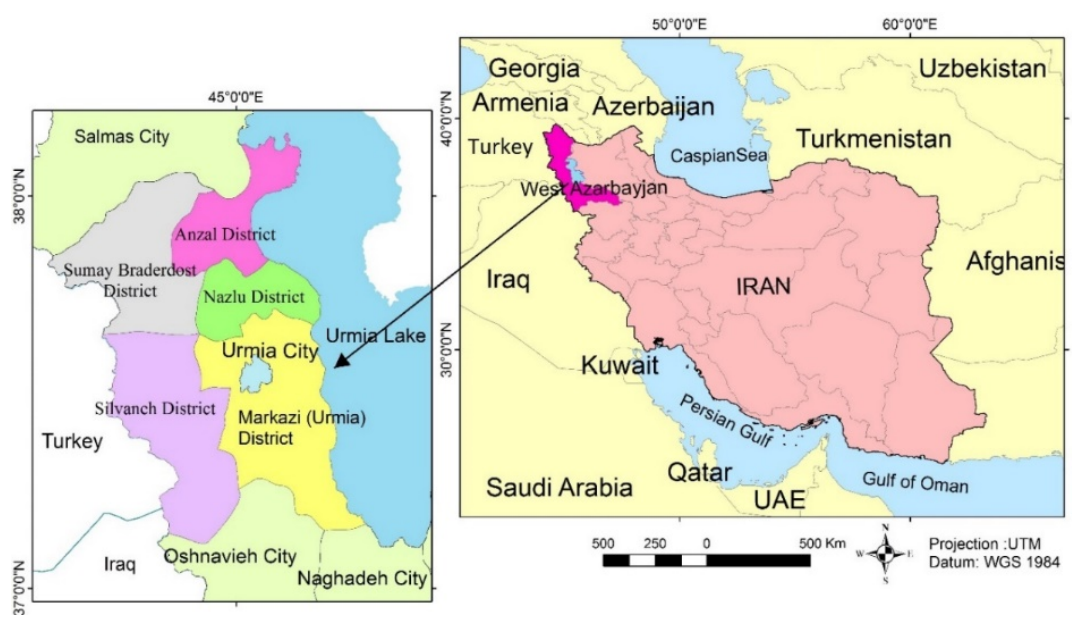

Figure 3. Iran, West Azarbayjan Province and the city of Urmia.

To evaluate urban changes and urban growth in Urmia, different datasets have been used as inputs. Landsat data were acquired for the years of 2004 and 2014 (ETM+ and OLI_TIRS, respectively) in order to extract the land use datasets for the region of Urmia. In this research, the maximum likelihood classification method was used to classify the images. The overall accuracies for the classified maps for the years of 2004 and 2014 were $88.52 \%$ and $90.67 \%$, respectively. Figure 4 shows the urban growth map of Urmia from 2004 to 2014. Analysis of land use changes in Urmia over time reveals that the city area has increased by about $38.1 \%$ from 6518 to 9003 hectares during ten years (2004 to 2014), reflecting Urmia's rapid urbanization in suburbs which caused destruction of agricultural lands. From this process, about $47 \%$ of agricultural lands were converted to urban areas. This means that the urbanization process in Urmia threatens the region's economy that relies on agriculture. Therefore, it is necessary to consider this issue in the future development planning where urban growth scenarios can help to manage the destruction of farmlands. Previous studies showed that urban growth depends on various driving forces including urban size, location priority, socio-economic conditions, and environmental issues. Table 1 shows the effective factors in the urban growth process and their relevant data $[59,62]$. The spatial variables in the urban growth process based on Table 1 were collected from different sources, converted to raster format, and loaded into the models (Figure 5).

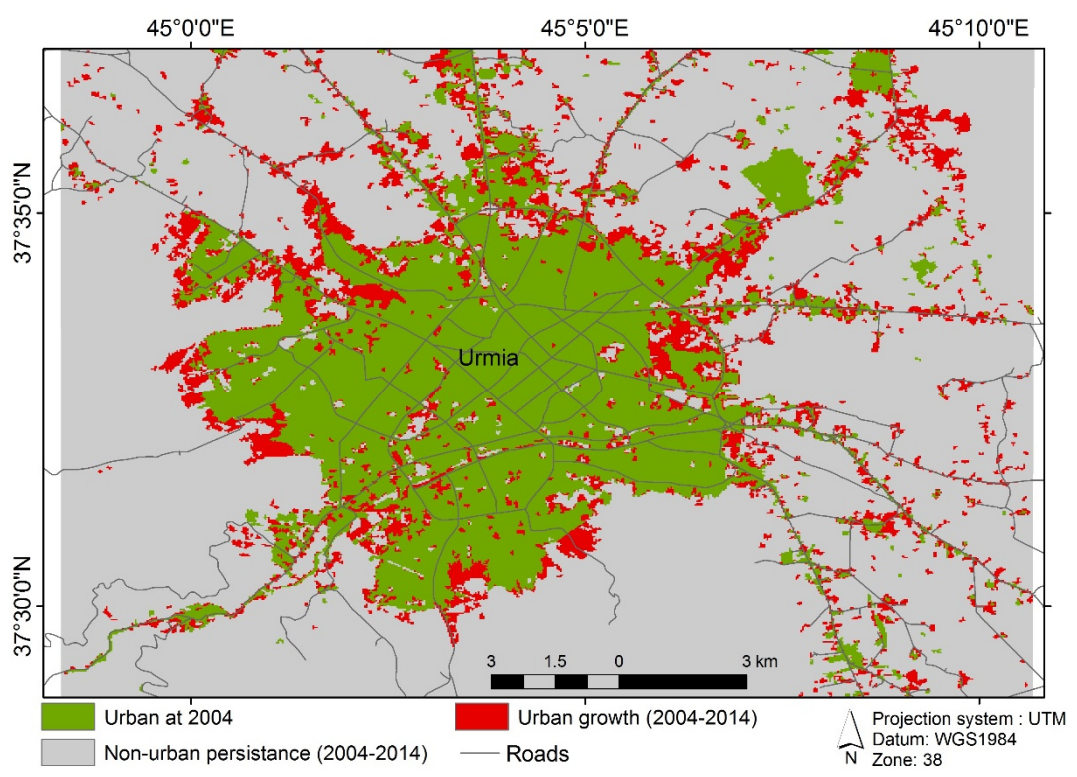

Figure 4. Urban growth in Urmia from 2004 to 2014. 
Table 1. Effective factors in urban growth process.

\begin{tabular}{ll}
\hline Variables [34,49,62] & Data Sources \\
\hline Land use and land cover maps & Landsat classified images, topographic map (2004 and 2014) \\
Slope and elevation maps & Topographic map (2004) \\
Distance from business center map & Topographic map and land use (2004) \\
Distance from population centers map & Topographic map (2004) \\
Distance from road networks map & Road networks (2004) \\
Environmental sensitive areas map & Environmental maps (2004) \\
\hline
\end{tabular}

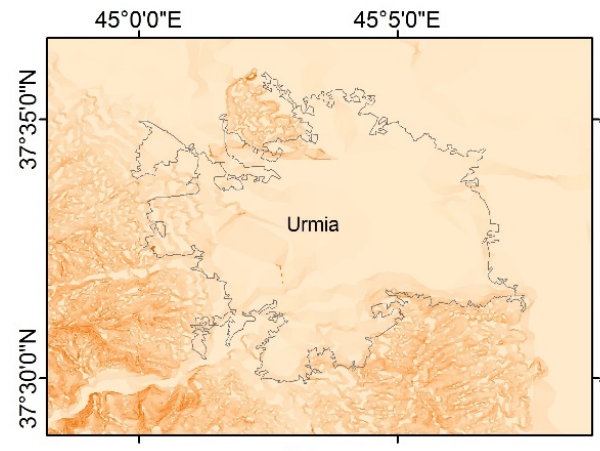

(a)

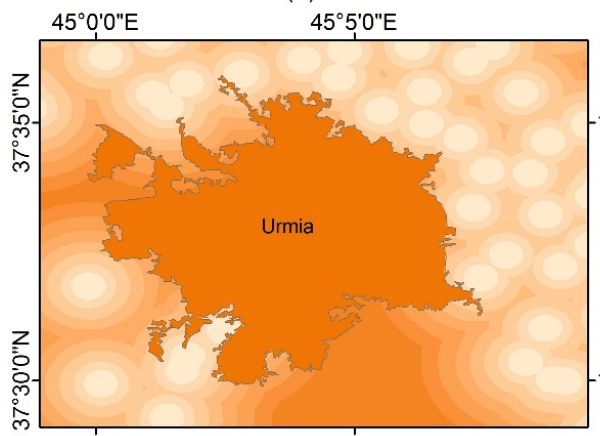

(c) $45^{\circ} 5^{\prime} \mathrm{O}^{\prime \prime} \mathrm{E}$

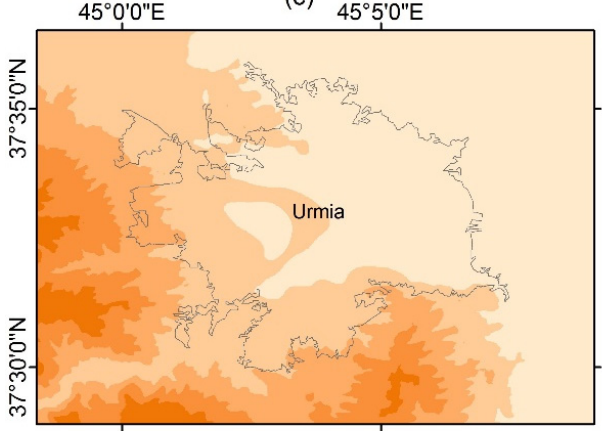

(e)

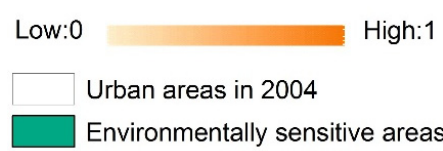

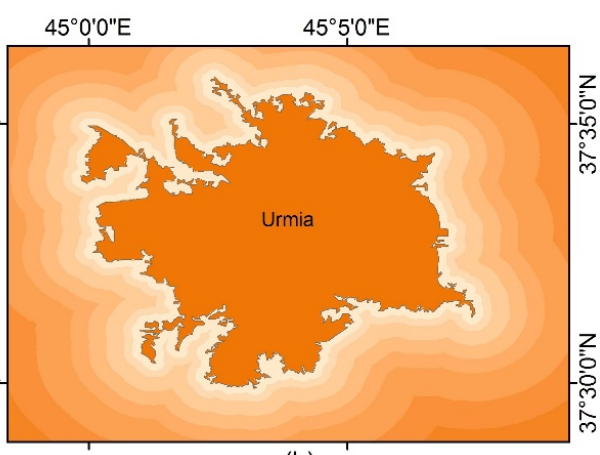

(b)

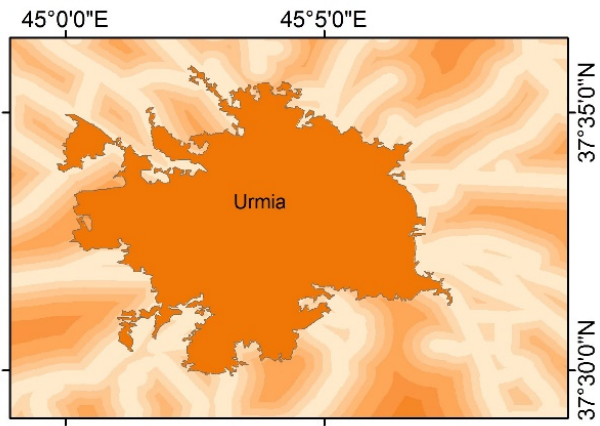

$45^{\circ} Q^{\prime} 0^{\prime \prime E} \quad$ (d) $45^{\circ} 5^{\prime} O^{\prime \prime} E$

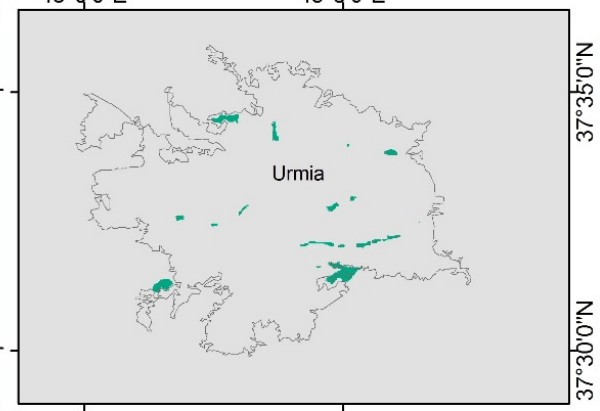

(f)

Projection : UTM

$\triangle$ Datum: WGS1984

Zone: $38 \mathrm{~N}$

Figure 5. Normalized data of urban growth process in Urmia. (a) Slope map; (b) Proximity to major business center map; (c) Proximity to population center map; (d) Proximity to major roads map; (e) Elevation map; and (f) Environmentally sensitive areas map.

Slope and elevation maps with resolutions $30 \mathrm{~m} \times 30 \mathrm{~m}$ were derived from a digital elevation model extracted from topographic maps produced by the national cartographic center of Iran. Slope and elevation maps are important factors in modeling urban growth because they input realism into 
the prediction model by representing the real morphology of the study area. Figure 5a,e illustrate the slope and elevation maps, respectively; the regions with the lowest values (slope and elevation) are suitable lands for urbanization in Urmia. A transportation network dataset was also used in this study; this dataset demonstrates the density of road network, showing the relationships among different land-uses. The proximity to the roads is calculated based on the Euclidean algorithm. Regions close to the roads have high suitability for urbanization (the lower values show high suitability). Another dataset used in the model considers environmentally sensitive areas such as forests, wetlands, floodplains, or environmentally sensitive lands that the future urban growth plan must preserve. Finally, other datasets used in this study include maps for the proximity to the major business center of the city and its neighboring population centers. According to Figure $5 b, c$, the suitability for urbanization is decreased by increasing the distance to these areas (the lower values show high suitability).

\section{Implementation and Simulation Results}

The PSO-CA and ABC-CA models for the simulation of urban growth of Urmia were developed in Matlab $^{\mathrm{TM}}$ and ArcGIS ${ }^{\mathrm{TM}}$ software based on the data processing flowchart presented in Figure 6. Urmia land-use maps for 2004 were considered for the base map. According to previous studies, the urban changes and urban growth are influenced by the integration of various factors such as geographical, environmental, and socio-economic factors [16]. To evaluate and model the urban growth in Urmia, the data corresponding to the variables of influence (as presented in Table 1 and shown in Figure 5) were prepared as raster layers and loaded into the models. As part of the tested models, features of CA such as the neighborhood radius were characterized. In this study the 3-pixel neighborhood radius was used. In the proposed models, CA calibration was performed using integration of ABC and PSO algorithms. The obtained transition rules for each model were applied on the base map (2004) in order to produce simulated maps for 2014. A sample of transition rules of CA can be represented in Table 2 .

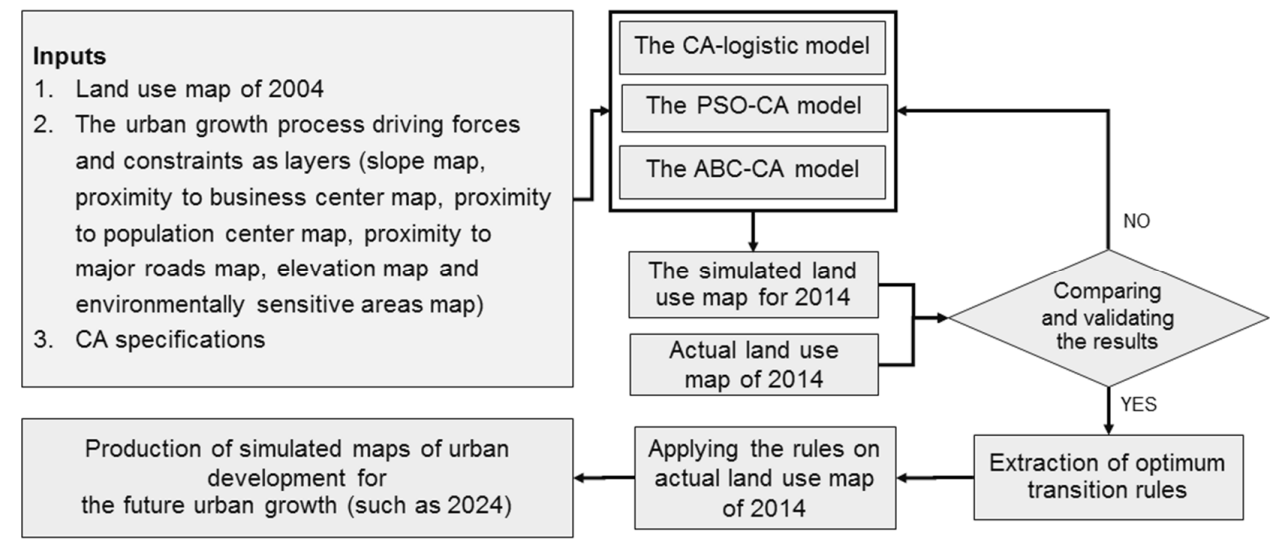

Figure 6. The proposed model for urban growth modeling by the ABC-CA, PSO-CA, and CA-logistic models.

Table 2. Part of the transition rules derived by using the proposed models.

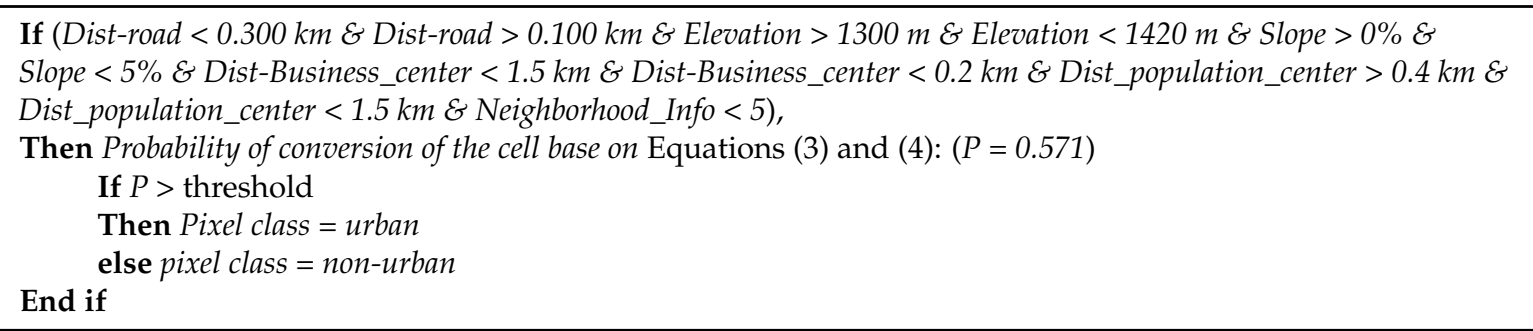


Next, a comparison of the simulated and actual land use maps of 2014 in the models was made as a measure of their goodness of fit, and if their similarities met the defined threshold criteria for each model based upon its setting and the future demand to land development, then the processes were stopped and the algorithms produced the optimum transition rules for the CA models. Otherwise, they were repeated until reaching the threshold criteria. These optimum rules have been applied on the land use maps of 2014 to achieve prediction of urban growth in Urmia for the next ten years (2024). These predictions can help urban planners to deal with the negative impacts of urban growth by considering various strategies.

In order to evaluate our urban growth models, we compared the result of the simulations against the reference map to quantify the goodness-of-fit of the models projections [72,73]. Comparisons between the observed and the simulated changes in the ABC-CA, PSO-CA, and CA-logistic models based on the areas of observed change simulated correctly (hits), observed persistence simulated as change (false alarms), observed change simulated as persistence (misses), and observed persistence simulated as persistence (correct rejections) [73] are shown in Figure 7.

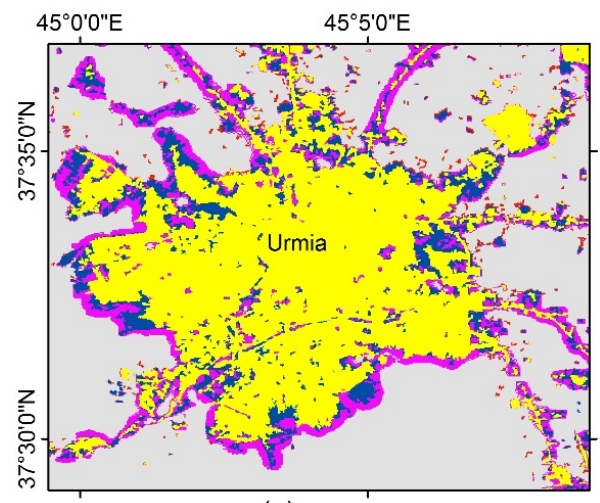

(a)

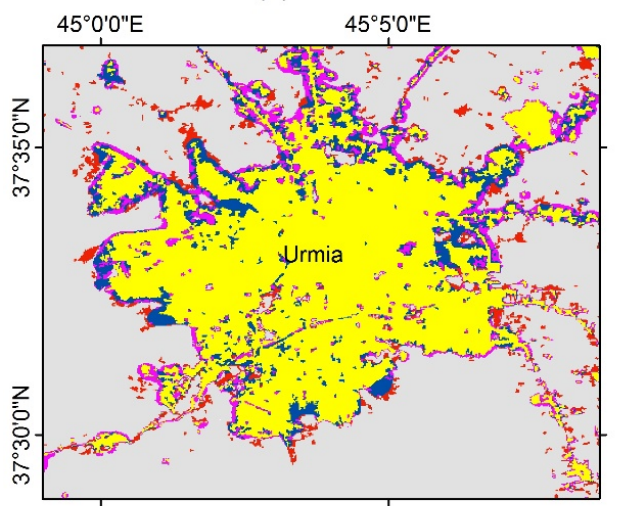

(c)

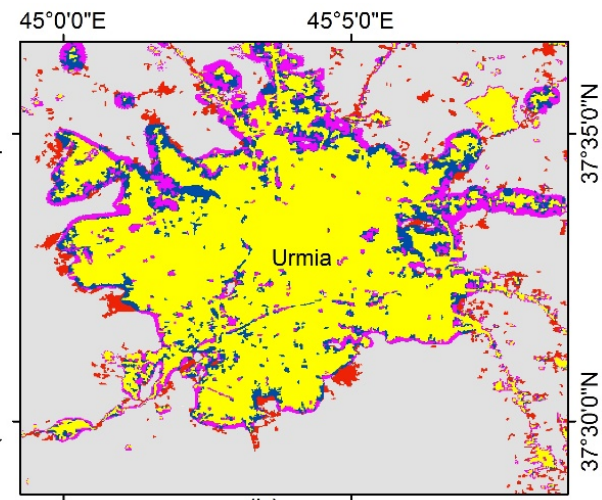

(b)

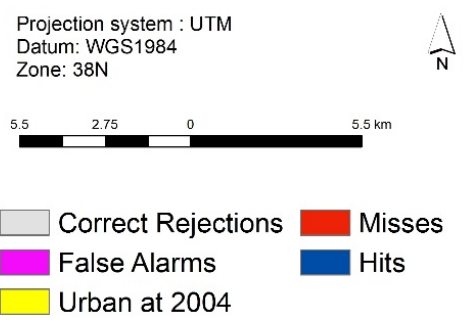


Overall, these outcomes verify that the ABC-CA model produced less simulation error and can perform better compared with the PSO-CA and CA-logistic models in modeling urban growth in Urmia.

In addition to the above validation, we used other statistical measures, such as figure of merits (FoM), overall accuracy (OA), and total operating characteristic (TOC), to assess the spatial accuracy of the models (Figure 8) [74]. The FoM is defined as the ratio of the intersection of the observed change and predicted change to the union of the observed change and predicted changes (Equation (8)) [74].

$$
F o M=B /(A+B+C+D)
$$

where $A$ is the area of error due to observed change predicted as persistence, $B$ is the area of correctness due to observed change predicted as change, $C$ is the area of error due to observed change predicted as the wrong category, and $D$ is the area of error due to observed persistence predicted as change. Figure 9 shows that the ABC-CA model has had better performance compared with that of the PSO-CA and CA-logistic models.

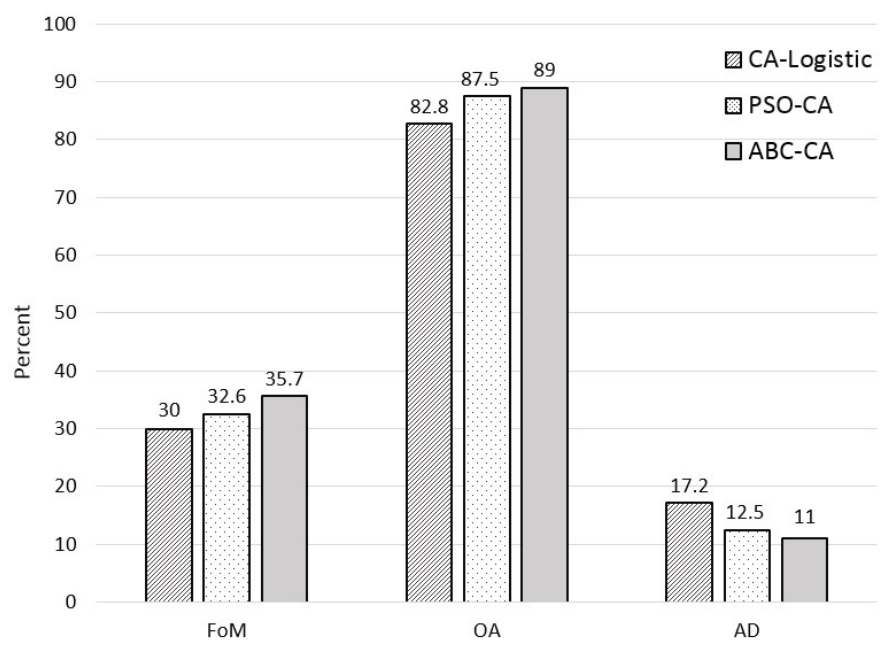

Figure 8. Statistical indices for the ABC-CA, PSO-CA, and CA-logistic models.

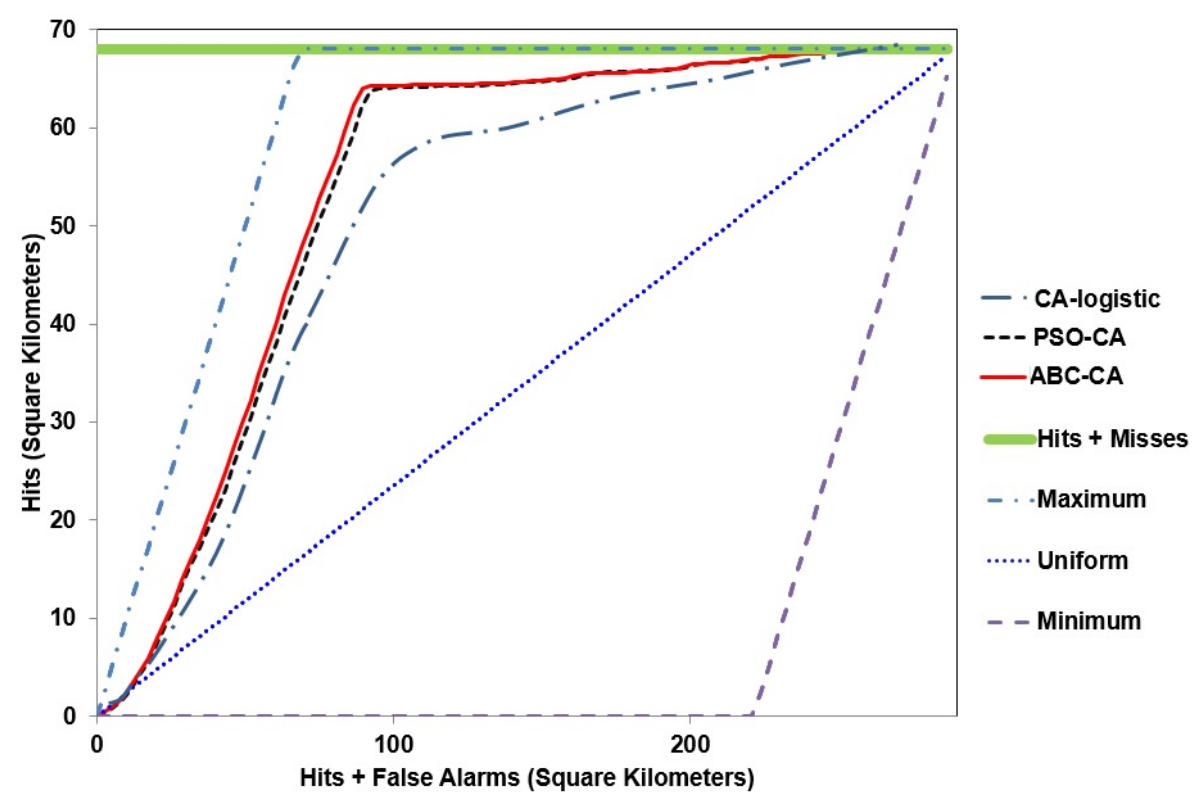

Figure 9. The total operating characteristics (TOC) plot of the ABC-CA, PSO-CA, and CA-logistic models. 
Another method that is widely used to validate urban growth and land change models is the relative operating characteristics (ROC) index proposed by Pontius and Schneider (2001) [75]. It evaluates the capability of the model in producing the best suitability maps independent of applying the threshold values to create a binary change map $[75,76]$. However, according to Pontius and Si (2014), several concerns exist regarding the use of ROC and the area under the curve of the ROC as an accuracy measure showing the summarization of the strength of the model [75]. The total operating characteristics (TOC) were introduced to deal with the ROC limitations. The consideration of multiple thresholds was accomplished by both ROC and TOC methods. TOC generates a graphical plot to reveal the information which shows a whole contingency table for all thresholds while ROC fails to do that. TOC shows the produced information of ROC and additional information such as the size of the number of observations (as the horizontal axis), the size of reference presence (the vertical axis), and information about the contingency table (Table 3). The contingency table presents accuracy statistics, including the total accuracy, the user accuracy, and producer accuracy. In Table 3, the main entries are hits $(H)$, misses $(M)$, false alarms $(F)$, and correct rejection $(C R)$ for a given threshold $t$. In the TOC plot, two boundaries as minimum and maximum exist that show the possible space of the TOC curve [75]. Figure 9 shows the TOC plots for the ABC-CA, PSO-CA and CA-logistic models. Comparing the two plots shows that the TOC curve of the ABC-CA model is closer to the maximum boundary representing the highest ranking observations of the index variable [59] rather than the TOC curve of the PSO-CA and CA-logistic models. This means that the ABC-CA model creates better results compared with those of the PSO-CA and logistic models. Table 4 shows the summary of the validation methods used in this research to evaluate the performance of the implemented models in urban growth modeling.

Table 3. Contingency Table.

\begin{tabular}{lcccc}
\hline \multirow{2}{*}{} & & \multicolumn{2}{c}{ Reference } \\
\cline { 3 - 5 } & Change & $H$ & $F$ & Total (Producer Accuracy) \\
\hline \multirow{3}{*}{ Simulated results } & Persistence & $H+F$ \\
& Persistence & $C R$ & $M+C R$ \\
& Total (user accuracy) & $H+M$ & $F+C R$ & $H+F+M+C R$ \\
\hline
\end{tabular}

Table 4. Summery of the validation of the used models for urban growth modeling.

\begin{tabular}{lccc}
\hline \multirow{2}{*}{ Validation Method } & \multicolumn{3}{c}{ Prediction Approach } \\
\cline { 2 - 4 } & CA-Logistic & PSO-CA & ABC-CA \\
\hline Overall accuracy (\%) & 82.8 & 87.5 & 89 \\
\hline Figure of merit (\%) & 30 & 32.6 & 35.7 \\
\hline False alarms (\%) & 15.1 & 7.7 & 6.2 \\
\hline Misses (\%) & 2.1 & 4.8 & 4.8 \\
\hline Allocation disagreement (\%) & 17.2 & 12.5 & 11 \\
\hline Correctly predicted unchanged cells (\%) & 75.4 & 81.4 & 82.9 \\
\hline Protection of agricultural areas from urbanization (\%) & 62.2 & 68.6 & 74.1 \\
\hline $\begin{array}{l}\text { Areas of the simulated gain of the urban lands in 2004-2014 } \\
\text { (the actual gain area of the city is 2500 hectares) (hectares) }\end{array}$ & 4960 & 3155 & 2824 \\
\hline TOC (closeness to maximum boundary) & low & medium & high \\
\hline
\end{tabular}

\section{Discussion}

In this study, swarm intelligence algorithms, in particular, the ABC and PSO algorithms, were integrated with CA to calibrate CA in the urban growth process because of their capabilities in 
dealing with complex relationships. Based on the land use maps derived from remote sensing images, the urban lands in Urmia during 2004-2014 increased by about 38\%. This rapid urban growth in Urmia destroyed agricultural lands and if this trend continues in the future, then more agricultural lands will continue to convert to urban lands. Agricultural landscapes have a significant role specifically in food production and water quality (2007). Therefore, preventing the conversion of rural areas to urban lands can lead to the achievement of some sustainability goals and can help to avoid the negative impacts of rapid urbanization. In this research, we provided approaches to estimate the possible future urban growth for improving decisions in urban planning. The approaches were attempted to predict the future urban growth in Urmia for the year 2024 while considering some limitation in the urban growth. The simulations reveal that Urmia tends to expand in its bordering areas especially in agricultural areas in the north and the northeast. Areas of the simulated gain of the urban lands for the ABC-CA, PSO-CA, and CA-logistic models were calculated as 2824, 3155, and 4960 hectares, respectively, whereas in reality this growth has been 2500 hectares during the period from 2004 to 2014 . The ABC-CA model produced a closer estimation. The results showed that conversion of agricultural areas to urban lands in the ABC-CA model are less compared with those of PSO-CA and CA-logistic models $(25.9 \%$ versus $31.4 \%$ and $37.8 \%)$.

Furthermore, our studies indicated that the rural-urban conversion in the eastern area of Urmia occurred because of its location relative to the major ring road (connecting the eastern parts of Urmia to its northern parts). The results reveal that proximity to the roads has had a prominent role in the urban growth in Urmia compared with other factors such as distance-based factors, slope, and elevation. Overall, it was realized that the eastern and northern parts of Urmia had more urbanization while in other areas urban growth occurred in the steep fringe wastelands.

In terms of performance, it was found that the convergence in the ABC-CA model was much faster compared with those of the PSO-CA model. In addition, implementation of the ABC-CA model was easier than the PSO-CA model because the $\mathrm{ABC}$ algorithm is considered to be highly flexible since it only requires two control parameters of maximum cycle number and colony size, while the PSO algorithm has more control parameters. In this experiment, the performance of the two models for modeling the urban growth in Urmia were assessed using Matlab2010 on a CORE i7 CPU with 8 GB RAM. The time taken to complete achieving the outcomes for the ABC-CA model was $31.6 \mathrm{~h}$, while the time required for the PSO-CA model to complete the process took $34.5 \mathrm{~h}$. This means that the ABC-CA model converged in a better time compared with that of the PSO-CA model.

This research investigated various factors to validate our proposed methods. In all evaluation indices, such as running time, convergence capability, flexibility, statistical measurements, and the spatial patterns, the ABC-CA model performance showed relative improvement in comparison with the PSO-CA model. Therefore, based on overall consideration of the indices we can confirm the superiority of the ABC-CA to the PSO-CA model.

Further research is needed on how to integrate other swarm intelligence algorithms or hybrid approaches such as ABC-PSO, Cuckoo-ABC, and Cuckoo-PSO with CA to achieve optimum transition rules in urban growth modeling. It seems that new hybrid algorithms can provide better predictions of future possible urban growth because of their ability to use the advantages and ignore the weaknesses of any of the individual approaches. The establishment of strong and adequate integration strategies is required for the establishment of useful and effective models for estimating future urban growth.

The use of CA for urban growth modeling has some limitations. It cannot reflect the feedback of the system and social behavior influence on the prediction and interact with the externalities driving the process. Also, it is not an appropriate method to consider aspatial dynamics such as behavior of resident, developer, and government agents in the modeling. An agent based model approach can help solve the drawback of CA by allowing it to respond to drivers and to various externalities dynamically. The coupling of agent based models with CA calibrating by swarm intelligence approaches could be used for the formation of hybrid models in order to improve the ability of the prediction results to take static and dynamic aspects of the urban growth process into consideration. 


\section{Conclusions}

CA is one of the most important models in the context of land use changes (such as urban growth) that has attracted the attention of researchers. The extraction of transition rules which define the future status of the cells in the CA model is a critical step. Nonlinearity and heterogeneity characterizes the urban growth process and influence the extraction of proper CA rules. Therefore, using artificial intelligence methods for discovering the rules for effective techniques when facing special conditions such as nonlinearity of the urban expansion is necessary. Recently, swarm intelligence based methods such as ABC and PSO in combination with CA have been shown to demonstrate good performance in urban change modeling. Additionally, some researchers have introduced several modifications on the $\mathrm{ABC}$ method to increase its performance. We constructed an ABC-CA model and applied two modifications on it to improve the performance of the model.

In this research, in order to compare the performance of the ABC-CA based method, we implemented a PSO-CA method that had good performance in previous studies [29] in urban CA based models. We selected 2004 as the base year for testing the estimated future urban land use changes and urban growth of Urmia. Simulation results were compared with their actual values for validation and simulation for a ten year period (2004 to 2014). Validation of the models' results was performed by various indices such as overall predication correctness and error, FoM, OA, AD, and TOC. The results verify that in comparison to the PSO-CA and CA-logistic models the ABC-CA model generates better results considering the validation indices in modeling the simulation of urban growth. The simulation results reveal that there was less conversion of agricultural lands to urban lands using the ABC-CA model compared to that of the PSO-CA and CA-logistic models. This is an important issue for Urmia, given that its economy is mainly based on agriculture, the ABC-CA model can better provide more realistic results for urban growth simulation.

Acknowledgments: The topographic map of the study area has been provided by Iran National Cartographic Center. The data on road networks are provided by Iran Road Maintenance and Transportation Organization. The data provided by the organizations are highly appreciated.

Author Contributions: Mahmoud Reza Delavar has given the initial idea of the research and helped in the methodology development. He has extensively reviewed the paper and extended the abstract, introduction, conclusion of the paper. He has interpreted the results and contributed in the major innovation and contribution explanation of the paper. Fereydoun Naghibi has undertaken the computational and modeling parts, written the draft paper and finalized the paper.

Conflicts of Interest: The authors declare no conflict of interest.

\section{References}

1. Fragkias, M.; Boone, C.G. Towards a New Framework for Urbanization and Sustainability: Linking Urban Ecology, Environmental Justice and Global Environmental Change; Springer: New York, NY, USA, 2013.

2. McKinney, M.L. Urbanization, biodiversity, and conservation. BioScience 2013, 5210, 883-890. [CrossRef]

3. Tang, Z.; Engel, B.A.; Pijanowski, B.C.; Lim, K.J. Forecasting land use change and its environmental impact at a watershed scale. J. Environ. Manag. 2005, 761, 35-45. [CrossRef] [PubMed]

4. Wiley, M.J.; Hyndman, D.W.; Pijanowski, B.C.; Kendall, A.D.; Riseng, C.; Rutherford, E.S.; Rediske, R.R. A multi-modeling approach to evaluating climate and land use change impacts in a Great Lakes River Basin. Hydrobiologia 2010, 6571, 243-262. [CrossRef]

5. LaBeau, M.B.; Robertson, D.M.; Mayer, A.S.; Pijanowski, B.C.; Saad, D.A. Effects of future urban and biofuel crop expansions on the riverine export of phosphorus to the Laurentian Great Lakes. Ecol. Model. 2014, 277, 27-37. [CrossRef]

6. Dewan, A.M.; Yamaguchi, Y.; Rahman, M.Z. Dynamics of land use/cover changes and the analysis of landscape fragmentation in Dhaka Metropolitan, Bangladesh. GeoJournal 2012, 77, 315-330. [CrossRef]

7. Frumkin, H. Urban sprawl and public health. Public Health Rep. 2002, 117, 201-217. [CrossRef]

8. Xu, X.; Du, Z.; Zhang, H. Integrating the system dynamic and cellular automata models to predict land use and land cover change. Int. J. Appl. Earth Obs. Geoinf. 2016, 52, 568-579. [CrossRef] 
9. Huang, G.; Gao, W. Simulation study on CA model based on parameter optimization of genetic algorithm and urban development. Proced. Eng. 2011, 15, 2175-2179. [CrossRef]

10. Shen, Q.; Chen, Q.; Tang, B.S.; Yeung, S.; Hu, Y.; Cheung, G. A system dynamics model for the sustainable land use planning and development. Habitat Int. 2009, 33, 15-25. [CrossRef]

11. Basse, R.M.; Omrani, H.; Charif, O.; Gerber, P.; Bódis, K. Land use changes modelling using advanced methods: Cellular automata and artificial neural networks. The spatial and explicit representation of land cover dynamics at the cross-border region scale. Appl. Geogr. 2014, 53, 160-171. [CrossRef]

12. Batty, M.; Xie, Y.; Sun, Z. Modeling urban dynamics through GIS-based cellular automata. Comput. Environ. Urban Syst. 1999, 233, 205-233. [CrossRef]

13. Guan, D.; Li, H.; Inohae, T.; Su, W.; Nagaie, T.; Hokao, K. Modeling urban land use change by the integration of cellular automaton and Markov model. Ecol. Model. 2011, 222, 3761-3772. [CrossRef]

14. Brown, D.G.; Riolo, R.; Robinson, D.T.; North, M.; Rand, W. Spatial process and data models: Toward integration of agent-based models and GIS. J. Geogr. Syst. 2005, 71, 25-47. [CrossRef]

15. Pijanowski, B.C.; Pithadia, S.; Shellito, B.A.; Alexandridis, K. Calibrating a neural network-based urban change model for two metropolitan areas of the Upper Midwest of the United States. Int. J. Geogr. Inf. Sci. 2005, 192, 197-215. [CrossRef]

16. Tayyebi, A.; Perry, P.C.; Tayyebi, A.H. Predicting the expansion of an urban boundary using spatial logistic regression and hybrid raster-vector routines with remote sensing and GIS. Int. J. Geogr. Inf. Sci. 2014, 28, 639-659. [CrossRef]

17. Dewan, A.M.; Yamaguchi, Y. Land use and land cover change in Greater Dhaka, Bangladesh: Using remote sensing to promote sustainable urbanization. Appl. Geogr. 2009, 29, 390-401. [CrossRef]

18. Mahboob, M.A.; Atif, I.; Iqbal, J. Remote sensing and GIS applications for assessment of urban sprawl in Karachi, Pakistan. Sci. Tech. Dev. 2015, 34, 179-188. [CrossRef]

19. Wu, Q.; Li, H.; Wang, R.; Paulussen, J.; He, Y.; Wang, M.; Wang, B.; Wang, Z. Monitoring and predicting land use change in Beijing using remote sensing and GIS. Landsc. Urban Plan. 2006, 78, 322-333. [CrossRef]

20. Alsharif, A.A.; Pradhan, B. Urban sprawl analysis of Tripoli Metropolitan City (Libya) using remote sensing data and multivariate logistic regression model. J. Indian Soc. Remote Sens. 2014, 42, 149-163. [CrossRef]

21. Store, R.; Kangas, J. Integrating spatial multi-criteria evaluation and expert knowledge for GIS-based habitat suitability modeling. Landsc. Urban Plan. 2001, 55, 79-93. [CrossRef]

22. Wu, F.; Webster, C.J. Simulation of land development through the integration of cellular automata and multicriteria evaluation. Environ. Plan. B Plan. Des. 1998, 25, 103-126. [CrossRef]

23. Wu, F. Calibration of stochastic cellular automata: The application to rural-urban land conversions. Int. J. Geogr. Inf. Sci. 2002, 16, 795-818. [CrossRef]

24. Riccioli, F.; El Asmar, T.; El Asmar, J.P.; Fratini, R. Use of cellular automata in the study of variables involved in land use changes. Environ. Monit. Assess. 2013, 185, 5361-5374. [CrossRef] [PubMed]

25. Pijanowski, B.C.; Brown, D.G.; Shellito, B.A.; Manik, G.A. Using neural networks and GIS to forecast land use changes: A land transformation model. Comput. Environ. Urban Syst. 2002, 266, 553-575. [CrossRef]

26. Tayyebi, A.; Pijanowski, B.C.; Tayyebi, A.H. An urban growth boundary model using neural networks, GIS and radial parameterization: An application to Tehran, Iran. Landsc. Urban Plan. 2011, 100, 35-44. [CrossRef]

27. Tayyebi, A.; Pijanowski, B.C. Modeling multiple land use changes using ANN, CART and MARS: Comparing tradeoffs in goodness of fit and explanatory power of data mining tools. Int. J. Appl. Earth Obs. Geoinf. 2014, 28, 102-116. [CrossRef]

28. Tayyebi, A.; Pijanowski, B.C.; Linderman, M.; Gratton, C. Comparing three global parametric and local non-parametric models to simulate land use change in diverse areas of the world. Environ. Model. Softw. 2014, 59, 202-221. [CrossRef]

29. Grekousis, G.; Manetos, P.; Photis, Y.N. Modeling urban evolution using neural networks, fuzzy logic and GIS: The case of the Athens metropolitan area. Cities 2013, 30, 193-203. [CrossRef]

30. Riccioli, F.; El Asmar, T.; El Asmar, J.P.; Fagarazzi, C.; Casini, L. Artificial neural network for multifunctional areas. Environ. Monit. Assess. 2016. [CrossRef] [PubMed]

31. Triantakonstantis, D.; Stathakis, D. Urban growth pre- diction in Athens, Greece, using Artificial Neural Networks. Int. J. Civ. Environ. Struct. Construct. Architect. Eng. 2015, 9, $234-238$.

32. Huang, B.; Xie, C.; Tay, R.; Wu, B. Land-use-change modeling using unbalanced support-vector machines. Environ. Plan. B Plan Des. 2009, 36, 398-416. [CrossRef] 
33. Tang, J.; Wang, L.; Yao, Z. Spatio-temporal urban landscape change analysis using the Markov chain model and a modified genetic algorithm. Int. J. Remote Sens. 2007, 28, 3255-3271. [CrossRef]

34. Batty, M. Cities and Complexity: Understanding Cities with Cellular Automata, Agent-Based Models, and Fractals; The MIT Press: Cambridge, MA, USA, 2007.

35. Feng, Y.; Liu, Y.; Tong, X.; Liu, M.; Deng, S. Modeling dynamic urban growth using cellular automata and particle swarm optimization rules. Landsc. Urban Plan. 2011, 102, 188-196. [CrossRef]

36. Clarke, K.C.; Gaydos, L.J. Loose-coupling a cellular automaton model and GIS: Long-term urban growth prediction for San Francisco and Washington/Baltimore. Int. J. Geogr. Inf. Sci. 1998, 127, 699-714. [CrossRef] [PubMed]

37. Shafizadeh, M.; Helbich, M. Spatiotemporal urbanization processes in the megacity of Mumbai, India: A Markov chains-cellular automata urban growth model. Appl. Geogr. 2013, 40, 140-149. [CrossRef]

38. Arsanjani, J.J.; Helbich, M.; Kainz, W.; Boloorani, A.D. Integration of logistic regression, Markov chain and cellular automata models to simulate urban expansion. Int. J. Appl. Earth Obs. Geoinf. 2013, 21, 265-275. [CrossRef]

39. Corner, R.J.; Dewan, A.M.; Chakma, S. Monitoring and prediction of land-use and land-cover (LULC) change. In Dhaka Megacity—Geospatial Perspectives on Urbanization, Environment and Health; Dewan, A.M., Corner, R.J., Eds.; Springer Geography: Berlin, Germany, 2014; pp. 75-97.

40. Al-Kheder, S.; Wang, J.; Shan, J. Fuzzy inference guided cellular automata urban-growth modeling using multi-temporal satellite images. Int. J. Geogr. Inf. Sci. 2008, 22, 1271-1293. [CrossRef]

41. Li, X.; Yeh, A.G.O. Neural-network-based cellular automata for simulating multiple land use changes using GIS. Int. J. Geogr. Inf. Sci. 2002, 164, 323-343. [CrossRef]

42. Azari, M.; Tayyebi, A.; Helbich, M.; Reveshty, M.A. Integrating cellular automata, artificial neural network, and fuzzy set theory to simulate threatened orchards: Application to Maragheh, Iran. GISci. Remote Sens. 2016, 53, 183-205. [CrossRef]

43. Samardžić-Petrović, M.; Dragićević, S.; Kovačević, M.; Bajat, B. Modeling urban land use changes using support vector machines. Trans. GIS 2016, 20, 718-734. [CrossRef]

44. Liu, Y.; Feng, Y.; Pontius, R.G. Spatially-explicit simulation of urban growth through self-adaptive genetic algorithm and cellular automata modelling. Land 2014, 3, 719-738. [CrossRef]

45. Liu, X.; Li, X.; Liu, L.; He, J.; Ai, B. A bottom-up approach to discover transition rules of cellular automata using ant intelligence. Int. J. Geogr. Inf. Sci. 2008, 22, 1247-1269. [CrossRef]

46. Cao, M.; Tang, G.A.; Shen, Q.; Wang, Y. A new discovery of transition rules for cellular automata by using cuckoo search algorithm. Int. J. Geogr. Inf. Sci. 2015, 29, 806-824. [CrossRef]

47. Liu, X.; Li, X.; Yeh, A.G.O.; He, J.; Tao, J. Discovery of transition rules for geographical cellular automata by using ant colony optimization. Sci. China Ser. D Earth Sci. 2007, 50, 1578-1588. [CrossRef]

48. Yang, J.; Tang, G.A.; Cao, M.; Zhu, R. An intelligent method to discover transition rules for cellular automata using bee colony optimization. Int. J. Geogr. Inf. Sci. 2013, 2710, 1849-1864. [CrossRef]

49. Liao, J.; Tang, L.; Shao, G.; Qiu, Q.; Wang, C.; Zheng, S.; Su, X. A neighbor decay cellular automata approach for simulating urban expansion based on particle swarm intelligence. Int. J. Geogr. Inf. Sci. 2014, 28, 720-738. [CrossRef]

50. Karaboga, D. An Idea Based on Honey Bee Swarm for Numerical Optimization; Computer Engineering Department, Erciyes University: Kayseri, Turkey, 2005.

51. Zhang, C.; Ouyang, D.; Ning, J. An artificial bee colony approach for clustering. Exp. Syst. Appl. 2010, 37, 4761-4767. [CrossRef]

52. Akay, B.; Karaboga, D. A modified artificial bee colony algorithm for real-parameter optimization. Inf. Sci. 2012, 192, 120-142. [CrossRef]

53. Karaboga, D.; Gorkemli, B.; Ozturk, C.; Karaboga, N. A comprehensive survey: Artificial bee colony ABC algorithm and applications. Artif. Intell. Rev. 2014, 421, 21-57. [CrossRef]

54. Bolaji, A.L.; Khader, A.T.; Al-Betar, M.A.; Awadallah, M.A. Artificial bee colony algorithm, its variants and applications: A survey. J. Theor. Appl. Inf. Tech. 2013, 47, 434-459.

55. Liu, Y.; Liu, D.; Liu, Y.; He, J.; Jiao, L.; Chen, Y.; Hong, X. Rural land use spatial allocation in the semiarid loess hilly area in China: Using a Particle Swarm Optimization model equipped with multi-objective optimization techniques. Sci. China Earth Sci. 2012, 55, 1166-1177. [CrossRef]

56. Census Information. Available online: http://www.amar.org.ir (accessed on 20 April 2012). 
57. Santé, I.; García, A.M.; Miranda, D.; Crecente, R. Cellular automata models for the simulation of real-world urban processes: A review and analysis. Landsc. Urban Plan. 2010, 96, 108-122. [CrossRef]

58. White, R.; Engelen, G.; Uljee, I. The use of constrained cellular automata for high-resolution modelling of urban land-use dynamics. Environ. Plan. B Plan. Des. 1997, 24, 323-343. [CrossRef]

59. Chen, Y.; Li, X.; Liu, X.; Ai, B. Modeling urban land-use dynamics in a fast developing city using the modified logistic cellular automaton with a patch-based simulation strategy. Int. J. Geogr. Inf. Sci. 2014, 282, 234-255. [CrossRef]

60. Cao, K.; Huang, B.; Li, M.; Li, W. Calibrating a cellular automata model for understanding rural-urban land conversion: A Pareto front-based multi-objective optimization approach. Int. J. Geogr. Inf. Sci. 2014, 28, 1028-1046. [CrossRef]

61. Li, X.; Yeh, A.G.O. Zoning land for agricultural protection by the integration of remote sensing, GIS, and cellular automata. Photogramm. Eng. Remote Sens. 2001, 67, 471-477.

62. Lu, C.; Wu, Y.; Shen, Q.; Wang, H. Driving force of urban growth and regional planning: A case study of China's Guangdong Province. Habitat Int. 2013, 40, 35-41. [CrossRef]

63. Bhandari, A.K.; Kumar, A.; Singh, G.K. Modified artificial bee colony based computationally efficient multilevel thresholding for satellite image segmentation using Kapur's, Otsu and Tsallis functions. Exp. Syst. Appl. 2015, 42, 1573-1601. [CrossRef]

64. Li, G.; Niu, P.; Xiao, X. Development and investigation of efficient artificial bee colony algorithm for numerical function optimization. Appl. Softw. Comput. 2012, 12, 320-332. [CrossRef]

65. Biswas, S.; Chatterjee, A.; Goswami, S.K. An artificial bee colony-least square algorithm for solving harmonic estimation problems. Appl. Softw. Comput. 2013, 135, 2343-2355. [CrossRef]

66. Alatas, B. Chaotic bee colony algorithms for global numerical optimization. Exp. Syst. Appl. 2010, 37, 5682-5687. [CrossRef]

67. Alizadegan, A.; Asady, B.; Ahmadpour, M. Two modified versions of artificial bee colony algorithm. Appl. Math. Comput. 2013, 225, 601-609. [CrossRef]

68. Kennedy, J.; Eberhart, R.C. Particle swarm optimization. In Proceedings of the IEEE International Conference on Neural Networks, Perth, Australia, 27 November-1 December 1995; Volume 5, pp. 1942-1948.

69. Alatas, B.; Akin, E. Chaotically encoded particle swarm optimization algorithm and its applications. Chaos Solitons Fractals 2009, 41, 939-950. [CrossRef]

70. Jiang, H.; Kwong, C.K.; Chen, Z.; Ysim, Y.C. Chaos particle swarm optimization and T-S fuzzy modeling approaches to constrained predictive control. Exp. Syst. Appl. 2012, 39, 194-201. [CrossRef]

71. Sadeghpour, M.; Salarieh, H.; Vossoughi, G.; Alasty, A. Multi-variable control of chaos using PSO-based minimum entropy control. Commun. Nonlinear Sci. Numer. Simul. 2011, 16, 2397-2404. [CrossRef]

72. Pontius, R.G., Jr. Quantification error versus location error in comparison of categorical maps. Photogramm. Eng. Remote Sens. 2000, 66, 1011-1016.

73. Pontius, R.G., Jr.; Cornell, J.D.; Hall, C.A. Modeling the spatial pattern of land-use change with GEOMOD2: Application and validation for Costa Rica. Agric. Ecosyst. Environ. 2001, 851, 191-203. [CrossRef]

74. Pontius, R.G., Jr.; Schneider, L.C. Land-cover change model validation by an ROC method for the Ipswich watershed, Massachusetts, USA. Agric. Ecosyst. Environ. 2001, 851, 239-248. [CrossRef]

75. Pontius, R.G., Jr.; Si, K. The total operating characteristic to measure diagnostic ability for multiple thresholds. Int. J. Geogr. Inf. Sci. 2014, 28, 570-583. [CrossRef]

76. Ahmed, S.J.; Bramley, G.; Verburg, P.H. Key Driving factors influencing urban growth: Spatial-statistical modelling with Clue-s. In Dhaka Megacity_Geospatial Perspectives on Urbanization, Environment and Health; Dewan, A.M., Corner, R.J., Eds.; Springer Geography: Berlin, Germany, 2014; pp. 123-145.

(C) 2016 by the authors; licensee MDPI, Basel, Switzerland. This article is an open access article distributed under the terms and conditions of the Creative Commons Attribution (CC-BY) license (http:/ / creativecommons.org/licenses/by/4.0/). 